\title{
At-Risk Students' Response to Learning Mathematics and Science in a Second Language
}

\begin{abstract}
The Malaysian government recently reverted to the English language as the medium of instruction in its education system for important content subjects such as Mathematics and the Sciences. This policy decision was made in the midst of widespread concern over the perceived falling standards of English language proficiency after the country had used Malay, the native language of the majority Malays, as the medium of instruction for almost two decades. This year marks the first year high school students will sit for the national standardized examinations in English. Dissenters to this policy shift in the language of instruction fear that many will suffer as a result of this change. In this study, the self reports of academically high and low performing students are compared in terms of their ability to perform language related tasks in Malay and the English language. Using the Chi-square statistic, the results of the yes-no responses given by the students indicate that while high performing students report no major difficulties in either language, responses from the low performing students indicate otherwise. Additionally open-ended responses to learning Science and Mathematics in a second language are also qualitatively analysed in order to obtain a more comprehensive view of the challenges these students may face. Several implications based on these results are also discussed.
\end{abstract}

Keyword: Teaching English as a Second Language, At-Risk Students, Teaching and Learning 